\title{
Quantitative mapping of fish habitat: A useful tool to design spatialised management measures and marine protected area with fishery objectives
}

\author{
O. Le Pape ${ }^{\mathrm{a}, *}$, J. Delavenne ${ }^{\mathrm{b}}, \mathrm{S} . \mathrm{Vaz}^{\mathrm{c}}$
}

\author{
${ }^{a}$ Agrocampus Ouest, UMR985 ESE Ecologie et santé des écosystèmes, F-35042 Rennes, France \\ ${ }^{\mathrm{b}}$ Ifremer, Laboratoire Ressources halieutiques, 150 Quai Gambetta, B.P. 699, 62321 Boulogne sur Mer, France \\ ${ }^{c}$ Ifremer, UMR EME 212, Av. Jean Monnet, BP171, 34200 Sète, France
}

*: Corresponding author : Olivier Le Pape, email address : olivier.le.pape@agrocampus-ouest.fr

\begin{abstract}
:
The delineation of essential fish habitats is necessary to identify, design and prioritize efficient marine protected area (MPA) networks with fishery objectives, capable, in addition to other possible objectives and functions of MPAs, of sustaining the renewal of marine living resources. Both the methods available to map essential fish habitats and the usefulness of these maps are discussed in this paper.

Generally, the first step to obtain maps of essential fish habitats consists in choosing one of the numerous existing statistical approaches to build robust habitat suitability models linking relevant descriptors of the marine environment to the spatial distribution of fish presence or density. When these descriptors are exhaustively known, i.e. maps are available for each of them, geo-referenced predictions from these models and their related uncertainty may be imported into Geographic Information Systems for the quantitative identification and characterization of key sites for the marine living resources.
\end{abstract}

The second part of this paper deals with the usefulness of such quantitative maps for management purposes. These maps allow for the quantitative identification of the different habitats that are required for these marine resources to complete their life cycles and enable to measure their respective importance for population renewal and conservation. The consequences of anthropogenic pressures not only fishing but also land reclamation, aggregate extractions or degradation of habitat quality (e.g. nutrient excess or xenobiotics loadings, invasive species or global change) - on living resources, may also be simulated from such habitat models. These quantitative maps may serve as input in specific conservation planning software based on the systematic conservation approach. Fish habitat maps thus may help decision makers to select relevant protection areas and design coherent MPA networks which objectives are to sustain fishing resources and fisheries.

\footnotetext{
Highlights

The delineation of fish habitats is needed to identify MPAs with fishery objectives. This paper reviews:

- The quantitative methods to map fish habitats and identify key sites for fishery resources.

- The usefulness of maps to measure the importance of habitats to sustain resources.

- The relevance of fish habitat maps to design MPA networks.
} 


\section{Introduction}

Many populations, particularly of fishes, are only remnants of their original numbers due to direct or indirect human pressure and, as such, need to be protected. Following the establishment of the Convention on Biological Diversity, the 2002 World Summit on Sustainable Development (Johannesburg) recommended to adopt an Ecosystem Approach to Fishery management to both achieve conservation of marine ecosystems and maximise economic profitability of fisheries (Brownman et al., 2004). If measures of regulation at stock scale remain necessary (e.g., limiting fishing pressure to maintain the size of the spawning stock; Hilborn and Walters, 1992), it has been agreed to develop complementary methods to manage ecosystems, in particular to establish a worldwide system of marine protected areas (MPAs) (Mora et al., 2006). MPAs are considered efficient instruments for the protection of critical habitats, biodiversity, and ecosystem functions (Leathwick et al., 2008) and there is growing evidence of their usefulness in the management of fisheries (Halpern and Warner, 2002; Gell and Roberts, 2003; Vandeperre et al., 2011; Mesnildrey et al., 2013).

Although marine reserve objectives increasingly include the protection of marine living resources to maintain fish populations and fisheries, uncertainties remain about their optimal design to that aim (Claudet et al., 2008; Mesnildrey et al., 2013). Marine reserves are considered for their ability to improve species conservation within their limits and fishery yields outside, through the export of fish and larvae to fished areas (Gell and Roberts, 2003; Grüss et al., 2011b). Their positive influence on densities, biomass, size structure and life history traits of living resources inside their limits is well established (Lester et al., 2009). However, there is still a high level of uncertainty regarding their impact on surrounding exploited areas (Sale et al., 2005; Gruss et al., 2011b; Mesnildrey et al., 2013).

Marine fish populations are not randomly distributed, but exhibit distributions that are structured both in space and time (Mello and Rose, 2005). A species distribution results from the combined action of several forces (Planque et al., 2011a), some of which are external (such as environmental conditions or food availability), whereas others are internal to the considered species, population or community (such as total population size; Aarts et al., 2013). The set of conditions required for individual survival and reproduction constitute the "ecological niche" within which a species may indefinitely sustain itself. The geographical projection of this fundamental niche corresponds to the habitat of the considered species (Chase and Leibold, 2003). The analysis of relationships between species and their habitats has always been a central issue in ecology and is used to investigate the role of the different factors that may affect a population and to characterize the mechanisms determining habitat suitability.

For numerous marine organisms, habitat requirements change over the course of their development (Harden Jones, 1968), resulting in distinct distributions along the life cycle; the displacement between these zones being ensured by passive or active migration (Grüss et al., 2011ab). Ontogenic habitat switching structures the spatial distribution of organisms from each phase throughout the entirety of their life cycles (van de Wolfshaar et al., 2011). Indeed, the life strategy of most marine fishes is characterized by high fecundity and high mortality in young life stages (Juanes, 2007). The low survival of eggs, larvae (Houde, 2008) and juveniles (Le Pape and Bonhommeau, in press.) strongly depends on abiotic and biotic environmental factors. This high mortality at early life stages has been identified as a main determinant of the abundance of marine populations (Houde, 2008) that reduces the correlation between the spawning biomass and the subsequent year class (Hilborn and Walters, 1992). As a consequence, the functionality of essential fish habitats, such as spawning or nursery grounds (Le Pape et al., 2003; van de Wolfshaar et al., 2011) but also migration routes along ontogenic migrations, is essential to sustain the renewal of marine fish populations (Iles and Beverton, 2000). Interactions between fisheries and species habitats 
must be included in management plans (Peterson, 2003) and there is a need to protect the ecological function of essential fish habitats, not only for sustaining marine fish population and associated fisheries (Hall, 1998) but also for conservation purposes (e.g. the protection of endangered species; Martin et al., 2012).

Planque et al. (2007) distinguished three types of habitats for given functions: potential, realized and effective. The potential habitat represents the suitable areas for the function studied. The realized habitat corresponds to the portion of the potential habitat that is effectively occupied at a given time. The effective habitat corresponds to that portion of realized habitat that will be proved to contribute the most to the survival of the species by allowing the completion of its life cycle (Dahlgren et al., 2006). Taking into account effective fish habitats in marine reserve design, thus protecting successive fish habitats along their life cycle (i.e., spawning, nurseries, feeding grounds, migration routes), for exploited and endangered species is of major importance. Larval, juvenile and adult habitat selection, and also mobility and ontogenic migrations along the life cycle, have a considerable influence on the efficiency of MPAs in reaching fisheries goals (Kaplan, 2009; Moffit et al., 2009). For mobile populations, MPAs should cover a large fraction of the total distribution area to offer effective protection (Grüss et al., 2011ab). Protecting targeted zones where animals are associated with particular developmental stages could be as effective, or even more effective, (Grüss et al., 2011a) than closing off large parts of the population distribution area to fishing and other anthropogenic activities. For instance, protecting restricted but highly productive areas where juvenile fitness is enhanced through optimal feeding conditions (Pelletier and Magal, 1996; van de Wolfshaar et al., 2011), establishing spawning area closures to preserve fecund individuals, to provide sufficient spawning habitat for optimal stock abundance and improve fish reproductive capacity, or temporarily closing migration routes should increase recruitment success and be especially effective (Mesnildrey et al., 2013).

Among suitable tools matching the ecosystem approach to fisheries (de Jonge et al., 2012), there is a need to identify and map essential fish habitats in order to improve design, and furthermore, to prioritize fishery oriented MPA networks, to ensure that they are efficient in maintaining the renewal potential of marine living resources. To that aim, it is possible to predict the geographic distributions of species through life stages from habitat mapping approaches (Rubec et al., 1999, Martin et al, 2009, Lauria et al., 2011); then to combine these life stages and/or species specific maps in multiscale Habitat Suitability (HS) maps (Brown et al., 2000; Store and Jokimaki, 2003); or to integrate these maps on portfolios for measuring integrated conservation value (Delavenne et al., 2012). HS maps are essential elements in the identification and prioritization of suitable areas for conducting spatial ecosystem assessments and conservation actions (Brown et al., 2000; Cogan et al., 2009). Especially, HS maps may answer questions about what exactly constitutes high value or even critical fish habitat for exploited (Fodrie and Mendoza, 2006) or endangered (Martin et al., 2012) species, and may provide information needed to conserve essential fish habitats (Stoner, 2003). The successive steps of the general and most widespread approach to build quantitative maps of essential fish habitats is described here first (defining goals and chosing species and habitats descriptors, modelling then mapping; Fig. 1). Then we focus on the usefulness of these maps to investigate and delineate fish habitat, to compare the respective importance of different habitats on population renewal and to estimate and/or to simulate the consequences of anthropogenic pressures on living resources. The use of these maps and quantitative information to prioritize protection areas and improve fisheries management systems is finally discussed. 


\section{Building quantitative maps of essential fish habitats}

Identifying factors that condition the spatial distribution of a given species represents the core of predictive geographical modelling in ecology. Habitat modelling (modelling species distribution) and Geographic Information Systems (GIS) are key tools that lead to a better understanding of species-environment relationships. Developing quantitative maps of fish distribution, based on environmental descriptors, requires successive steps (Fig. 1): (i) selecting the species accounted for, (ii) fitting and evaluating HS models that relate species or stage specific distribution to environmental factors, (iii) using HS indices from model outputs to create predicted distribution maps within a Geographic Information System (GIS) and (iv) combining these maps to help decision making.

\subsection{Developing HS models for marine fish communities, populations or life stages}

\subsubsection{Selecting study areas, species and life stages}

Designing efficient MPA networks to maintain sustainable living resources and fisheries requires the identification of priority areas (Delavenne et al., 2012) for both conservation purposes (e.g., conservation of endangered species) and fisheries related ecosystem services (Barbier et al., 2011). To that aim, and within the framework of an ecosystem approach (Brownman et al., 2004; de Jonge et al., 2012), the European Commission (EC) is promoting the concept of marine spatial planning to improve the management of marine activities. Accordingly, for management objectives to be efficiently achieved, information from habitat maps needs to represent habitats at a spatial scale relevant at the ecosystem and fish population level (Le Pape et al., 2003; Planque et al., 2011a), to allow accurate estimates to be made of the potential effects of pressure and protection. Therefore, the spatial extent of essential fish habitat mapping must take into consideration the scale of relevant ecosystem processes and the related spatial shifts in fish population structure.

The following task of the procedure involves selecting communities (Vaz et al., 2007), fish species and life stages to be included in the mapping procedure (Martin et al., 2009). To meet the requirements of efficient MPA networks, this selection should include (i) species of main interest for fisheries (Riou et al., 2001; Le Pape et al., 2003; Fodrie and Mendoza, 2006), (ii) keystone species for fish communities and the ecosystem (Brown et al., 2000; Smith et al., 2011) and (iii) Endangered, Threatened and Protected (ETP) species (Martin et al., 2012).

Species selection usually takes into account both the aforementioned requirements and data availability for candidate species. To evaluate resource distribution and requirements, access to a large amount of data is necessary. These data are generally based on scientific surveys, less influenced by the sampling bias generally present in other types of data (e.g., fisheries catches). However, gathered information seldom covers the entirety of a given ecosystem nor is it available regularly over time. These observations, too rare and carried out on restricted periods and zones, result in an incomplete understanding of the ecosystem functioning and the impact of the multifarious human pressures and their interactions. When aggregating data from various source, data heterogeneity constantly dampens efforts at meta-analyses of data, as sampling protocols often differ. Thus, data to be used for habitat mapping should be given special attention with regard to quality, reliability, standardization and relevance. Two main categories of fish survey data may be used as response variables to develop HS indices (Fig. 1): occurrence and/or density (Rubec et al., 1999). The availability of large sets of reliable spatialized survey data, for several periods, to account for seasonal and interannual variability of fish distribution and abundance (Sluka et al. 2001; Le 
Pape et al., 2003; Loots et al., 2010), will drive species selection and, if necessary, lead to additional surveys (Guisan and Zimmermann, 2000).

When the list of species is finalised, knowledge on their life cycles and levels of dependence on specific habitats at particular developmental stages - e.g. spawning (Loots et al., 2010) and/or juvenile growth (Beck et al., 2001; Le Pape et al., 2003) - in addition to availability of size and/or age structured data allowing estimation of life stages, will drive the need and opportunity to discriminate life stages in HS models and maps.

\subsubsection{Collating available environmental factors that drive fish distribution}

Habitat occupation results from the influence of a large number of constraints. These constraints may be of very different nature, and are linked either to the individuals" external environment, or to the individuals themselves, whether they belong to the studied population/species or other ones (Ashcroft et al., 2010; Grüss et al., 2011a; Planque et al, 2011a; Aarts et al., 2013). In order to identify factors controlling species spatial distribution, HS models may be used to link the response of a population to different control hypotheses, which can be external (geographic location, environment, associated fauna) or internal to the population (spatial autocorrelation, population size, age structure). With regard to available knowledge and data, HS models are often only based on hypotheses on how external environmental factors control species distribution and/or life stages (Guizan and Zimmermann, 2000), although their capability to explain the observed distribution may sometimes be limited when they are used alone. Indeed, although many other factors may be responsible for constraining fish distribution, in this paper, like most studies dealing with habitat mapping (e.g. MacNally, 2000; Boisclair, 2001; Austin, 2007; Rushton et al., 2004; Araujo and Guisan, 2006; Guisan et al., 2006; Randin et al., 2006), we will generally reduce fish habitat to the environmental conditions suitable for a given population.

Before developing HS indices, there is a need to select the potential driving environmental factors of habitat choice and distribution for each of the retained species and life stages (Merow et al., 2013). Both abiotic (generally non-consumable habitat features) and biotic factors, including both consumable resources and non-consumable features, drive habitat choice and species distribution (Hayes et al., 1996) at different scales (Meng et al., 2005; Grüss et al., 2011a; Aarts et al. 2013). The environmental variables retained as potential descriptors in HS models must be selected in relation to these species and any life stagespecific requirements (Harden Jones, 1968; Le Pape et al., 2003; Loots et al., 2010).

The final aim is to develop fish HS maps by using models in a GIS to predict HS for a combination of habitat layers (Rubec et al., 1999; Fig. 1). To achieve this goal, there is a need for an exhaustive knowledge of retained descriptors, i.e. obtaining static and/or temporal maps of the factors used in HS models. Therefore, the selection of environmental descriptors is a compromise between driving factors and available data. In particular, biotic conditions (e.g. food availability and predation) are essential driving factors of habitat choice and significantly improve the description based on physical descriptors and the power of HS models (Diaz et al., 2003; Le Pape et al., 2007). There is a clear interest for the integration of biotic variables and a relative increase of the spatial resolution in approaches linking fish species to habitat (Johnson et al., 2012). Nevertheless, exhaustive fine scale knowledge about relevant biotic factors is presently seldom available and habitat mapping is predominantly based on abiotic factors only. 


\subsubsection{Coupling fish and environment data within a GIS}

Selected environmental descriptors are included in a GIS, which allows different layers of data to be intersected to obtain a stratification of the study area based on environmental parameters (Fig. 1). Information on physical and geographic factors is combined with survey data; the latter, identified from the geographic position of samples, are imported into the GIS to associate, for each sample, the local values of the related environmental descriptors. This association also needs to account for the sampling date when temporal maps are used (Le Pape et al., 2003).

\subsubsection{Developing an HS model}

For the purpose of statistical modelling of species habitat, methods aim to define an HS for a species by providing a numerical estimate of species response (e.g. in terms of abundance and/or presence probability) to changes in one or more environmental factor(s). There are numerous statistical modelling techniques to predict species distribution and several methods may be used to reach this objective. The first criterion driving the choice of an HS model is related to fish data. Indeed, fish occurrence and fish density are described by different methods in habitat models:

When only occurrence data are available, the modelling approach covers only the identification of determining conditions for fish and/or life stages to survive (Galparsoro et al. 2009). These are called ecological niches (Sillero, 2011) and are based on canonical response variables, allowing first the identification, then the mapping of suitable habitats (Rotenberry et al., 2006). Logistic regressions (Store and Jokimaki, 2003; Norcross et al., 1999) and their generalized form (Generalized Linear Models (GLM) or Generalized Additive models (GAM), using Bernouilli distribution) are widely used to describe presence/absence data. An alternative method consists of using multivariate factorial analysis, such as canonical analysis, linear discriminant function analysis (Norcross et al., 1997), redundancy analysis (Whaley et al., 2007) or fourth corner analysis (Legendre et al., 1997) to describe fish assemblages structure or functionalities. Another widely used method, the EcologicalNiche Factor Analysis (ENFA; Hirzel et al., 2001), computes suitability functions by comparing species distribution within the eco-geographical variable space with that of the whole set of cells. The ENFA was created to predict faunal distributions sensitive to erroneous absences (Hirzel et al., 2001). ENFA is considered particularly advantageous because it does not require absence data (Hirzel, et al., 2006; Galparsoro et al., 2009), allowing for the use of non-survey observation data, and especially data compiled by volunteer opportunistic observations and sightings (Edgar and Stuart Smith, 2009) in HS modelling, particularly for endangered species and conservation purposes. Other recent advances allowed the development of methods to fit presence distribution on presence-only data (e.g. MaxEnt free software; VanDerWal et al., 2009; Merckx et al., 2011; McDonald et al., 2013; Merow et al., 2013).

A wider array of models has been developed to describe and predict habitat distribution from density data, and the variety of available statistical techniques is growing (Guisan and Zimmermann, 2000, Guisan and Thuiller, 2005, Austin, 2007, Guisan, et al., 2006):

- HS indices based on mean calculation (Rogers, 1992; Brown et al., 2000; Vinagre et al., 2006) allow the comparison of mean densities in different habitats, described in classes.

- Ordination, classification techniques and categorical analysis regression trees (Fodrie and Mendoza, 2006; Froeschke and Froeschke, 2011) are factorial analysis allowing to discriminate classes of HS based on environmental descriptors (Norcross et al., 1999). 
Neural networks provide an alternative classification procedure that is rarely used in HS modelling (Guisan and Zimmermann, 2000),

- Ordinary multiple regression, linear models and GLMs are widely used for modelling species distribution (Riou et al., 2001; Whaley et al., 2007, Lauria et al. 2011),

- Polynomial regression (Rubec et al., 1999) and locally weighted approaches (i.e. General Additive models, GAM; Stoner et al., 2001; Kupschus, 2003; Francis et al., 2005) require more extensive datasets, but allow to describe non-linear and more complex responses to habitat descriptors (Loots et al., 2007, Vasconcelos et al., 2010).

- Fitting linear or additive models to fish data usually runs up against the problem of large amounts of null values in survey datasets. As such zero-inflated data do not fit with any of the exponential family of distributions, required conditions for GLM or GAM approaches are frequently not met. To solve this problem, densities could be described with zero-inflated models. For instance, delta models treat presence/absence and positive density values in two different sub-models (Stefansson, 1996); a binomial distribution for presence and another GLM (Le Pape et al., 2003) or GAM (Barry and Welsh, 2002; Vasconcelos et al., 2010) for positive abundance values are fitted separately then coupled in order to estimate HS (Calama et al., 2011). Alternative methods, e.g. compound Poisson process or Tweedie distribution, have also been implemented to analyze zero-inflated data (Trimoreau et al., 2013). As abundance is represented by two sources of data with different meanings, i.e. the level of non-zero catch rates and the probability of catching species (or the life stage), a model that integrates both kinds of data (Ye et al., 2001) provides complementary information on HS (Le Pape et al., 2004; Trimoreau et al., 2013).

- An alternative to zero-inflated models is the use of non-parametric correlation coefficients (Norcross et al., 1995). In particular, use of regression quantiles allows linear model parameters to be estimated near the upper bounds of the distribution (Eastwood et al., 2001; Planque et al., 2008, Vaz et al., 2008). This technique is adapted to estimate the effect of factors limiting species abundance (Hiddink, 2005). The predictions resulting from an upper quantile illustrate the spatial distribution of a species in ideal conditions and tend to describe potential distribution patterns that highlight every possible area exhibiting suitable conditions to the studied species, including those areas that are not necessarily used. As previous models provide a spatial representation of the average realized habitat, this approach, in the same way as environmental envelopes (Guisan and Zimmermann, 2000; Cheung et al., 2009), allows the potential habitat to be considered (Sillero, 2010). As realized habitat maps represent simulated distributions, derived from field observations, potential habitat maps aim to predict distributions from potential living constraints and represent minimum requirement (Guisan and Zimmermann, 2000).

Other advances allowed the development of methods to fit models based on categorical data (Mieszkowska et al., 2013), when density is only available from a qualitative description, but such data, as their use for fish habitat suitability modelling, are scarce.

\subsubsection{Choosing a modelling method, estimating uncertainty and evaluating habitat models}

Habitat modelling involves three steps: (i) choosing the type of model that is best adapted to the data, (ii) selecting the model, (iii) evaluating its adjustment, predictive capacity and uncertainty.

Model selection involves implicit consideration of the respective contributions of the explanatory factors tested against species response. Factors that do not contribute 
significantly to this response are withdrawn from the model. The present paper focuses on habitat mapping and is not a review of the appropriate procedures involved in fitting and selecting HS models. There are numerous recent reviews available on predictive habitat distribution modelling (Guizan and Zimmermann 2000, Segurado and Araujo, 2004; Vaughan and Ormerod, 2005; Maggini et al., 2006; Moisen et al., 2006; Elith et al., 2006) which provide guidelines to choose a method with regards to both study objectives and statistical criteria.

It is nonetheless especially important to spot that the noisy and redundant nature of data gathered in the natural environment largely complicates the construction and the statistical and ecological relevance of the models. Many developments were deployed to mitigate, at least partially, these issues and we suggest referring to the following references to consider methodological problems linked to HS models: Ashcroft et al. (2012) focused on methods related to occurrence models. Power et al. (2000) and Maravelias (2001) highlighted frequent problems that occur when covariates and factors used as environmental descriptors are autocorrelated. In such case of habitat clustering, explanatory variable significance may be over-estimated, which compromises the identification of the relevant factors. Graham (2003) proposed an overview of methods dealing with such colinearity in descriptors. Ashcroft et al. (2010), Planque et al. (2011a) and Blowes and Connoly (2012) provided important warnings on the dynamic nature of spatial distribution and the importance of processes linked to dispersal and spatial covariance. Accordingly, Lichstein et al. (2002), Calama et al. (2011) and Ashcroft et al. (2012) focused on problems linked to spatial autocorrelation in habitat models and related solutions. De Knegt et al. (2010) and Gottschalk et al. (2011) insisted on the importance of scale effects in HS models.

Once HS models are fitted, an extremely important part of the procedure is evaluating their robustness and their capacity to predict HS (Vasconcelos et al., 2013). To that aim, as long as there are enough observations, the initial dataset may be, as a preliminary, split randomly into calibration and validation subsets. The first is used to calibrate the model whereas the second is used to evaluate the quality of model predictions (Guisan and Zimmermann, 2000). Models must be tested on both of these datasets, using the model to predict response variables, based on predictor variables to measure their fit (Vasconcelos et al., 2013). This methodology allows the evaluation of model accuracy and robustness (Olden et al., 2002; Power, 1993). For presence models, testing predictive capacity could be done with the Area Under the Curve (AUC) (Elith et al., 2006; Townsend Peterson et al., 2008; Merow et al., 2013; Hattab et al., 2013). For models based on density, the predictive capacity could be tested according to correlation of the relation density observed versus density predicted by the model (Pineiro et al., 2008). This validation procedure is especially important: a lack of assessment could lead to spurious conclusions from non-robust HS models with poor and/or biased predictive power (Planque et al., 2011b; Vasconcelos et al., 2013). This procedure of post-validation may also be used to select the relevant descriptors based on the predictive power of the candidate models (Loots et al., 2010, Loots et al., 2011). Moreover, testing the model in a wide range of situations could further define the range of applications for which model prediction is suitable (Guisan and Zimmermann, 2000).

In HS models, the measure of projective uncertainty is of particular importance because data on fish spatial distribution have to be known with a sufficient level of confidence in order to be useful for further management purposes (Planque et al., 2011b). "Nature is too complex to be predicted accurately from models" (Guisan and Zimmermann, 2000), and there are several reasons why residual variability is important in HS models (Le Pape et al., 2003; Planque et al., 2011b): uncertainties can arise from observation processes, and especially data paucity, small-scale variability and temporal variability, from the lack of maps of important environmental descriptors, and from model formulation. Minimising uncertainties requires a balance between model parsimony, generality, reality and precision (Guizan and Zimmermann, 2000; Rotenberry et al., 2006). Residual variability is frequently high in fish 
habitat models (Le Pape et al., 2007; Trimoreau et al., 2013) and problems linked to unexplained variability and uncertainty in model estimates are especially important (Vasconcelos et al., 2013). In general, not enough attention is paid to most sources of uncertainty and projections are currently less reliable than generally thought (Planque et al., 2011b). Uncertainty in parameter estimates could be assessed from statistical models, and related confidence intervals could be provided, even for delta models that require specific approaches to combine uncertainty with the sub-models (Fletcher, 2008; Calama et al., 2011). Nevertheless, other sources of uncertainty are rarely accounted for (Planque et al., 2011b). To that end, the use of Bayesian methods in HS modelling provides the advantage of incorporating all information within a probabilistic framework (Stewart-Koster et al., 2013). Bayesian methods enable experts" knowledge on sources and levels of uncertainty to be considered and to construct credibility intervals within statistical models to provide inferences, together with an appraisal of estimate and prediction uncertainty (Rivot et al., 2004).

\subsection{Coupling HS models and GIS to create predictive distribution maps}

To develop predictive habitat maps, the HS model parameter estimates are used to re-code (Eastwood et al., 2001) the environmental layers so as to produce maps reflecting HS (Fig. 1). The same method could be used to produce maps of uncertainty in order to provide an overview of the prediction quality. Accordingly, from statistical models, prediction uncertainty varies with the values of the predictors, and this could lead to spatial differences in the accuracy of HS estimates.

Moreover, when models are fitted on fish density data, HS model prediction and GIS may be coupled to calculate an index of abundance, based on the extent and surface of the geographic units, to estimate the respective contributions of the different sectors to the overall fish or life stage distribution (Riou et al., 2001; Le Pape et al., 2003; Rochette et al., 2010):

- Surface areas of various combinations of descriptors are calculated within a GIS.

- For each combination, "number of fish" is calculated as the product of this surface area multiplied by the corresponding density value, as estimated from the model.

"Number of fish" can then be used to determine the contribution of the different habitat combinations to the total population as a percentage of the total number of fish represented by the different habitat combinations (i.e. effective fish habitat; Dahlgren et al., 2006).

\section{Fish habitat maps and decision-making for spatial management}

In addition to its interest in ecological research, predictive geographic modelling may be used for multipurpose applications, to investigate the function and importance of specific habitat to a fish population, to assess the impact of human use and other environmental changes over species distribution, to improve animal atlases (e.g. Martin et al., 2009), to help decision making in spatial planning of fisheries and other human activities, to establish conservation priorities, and/or to design fisheries-oriented MPAs. 


\subsection{Identifying essential and effective fish habitats}

From maps describing fish or life stage presence, i.e. predicted maps of ecological niches (Sillero, 2011), realized or potential niches can be identified spatially. Ecological niche maps provide powerful tools for identifying suitable habitat in data poor environment, when density or even absence data are lacking. Such methods are especially suitable for species over large spatial extents (Rotenberry et al., 2006), when the models are based on presence data from various and non-standardized sources. Predicted maps of presence could also be especially useful for ETP species (Martin et al., 2012) for which an ecological niche must be preserved for conservation purposes. Predicted maps of ecological niches could also be combined in order to identify hotspots of realized or potential biodiversity, by overlaying distribution maps of all considered species (Cheung et al., 2009).

When maps are based on fish densities, several approaches allow the identification of fish habitats. According to Beck et al. (2001), a combination of environmental factors characterizes essential fish habitat for particular fish species if it contributes disproportionately to the total number of fish on a per-unit-area basis relative to other habitats (i.e. if an estimated HS is locally much higher). Even if a habitat covers only a small area, it should be considered important if it produces more fish per unit of area. It is important to conserve and prevent the destruction of these habitats that contribute disproportionately to the population, and HS maps allow us to focus on their location. In addition to this definition, based on per unit of area, Dahlgren et al. (2006) developed a framework for evaluating fish habitats based on their overall contribution to populations, and introduced the concept of Effective Fish Habitat; they referred to habitats that make a great overall contribution, regardless of area coverage. Accordingly, Riou et al. (2001) and Le Pape et al. (2003) assessed effective nursery habitat for populations of estuarine and coastal nurserydependent flatfish species along the French Coasts, using the number of juveniles per habitat type (i.e. the product of the surface area by the corresponding density value) to determine the contribution of the different habitats to the population as a percentage of the total number of juveniles at the population scales. For example, for the common sole in the Bay of Biscay, Le Pape et al. (2003) showed the important role of very shallow ( $<5 \mathrm{~m}$ depth) areas in providing nursery grounds for the population; these areas represented only one quarter of the coastal area within the $50-\mathrm{m}$ depth limit, but contributed more than $80 \%$ of the total number of juveniles. For the plaice in the eastern English Channel (Riou et al., 2001), the respective contributions of different coastal sectors showed the main role played by one single productive coastal area (hosting half of the juveniles) for population supply.

Most species distribution modelling approaches are based on an estimate of the mean or median (central tendency) species response (abundance or presence probability) to environmental factors (Oksanen and Minchin, 2002). Such techniques are extremely useful to represent spatial distribution, but do not properly estimate the limiting effects of the environment on species (Cade et al., 1999). Indeed, the real response of a species to a given limiting factor can only be quantified if all other factors occur at non-limiting levels (Hiddink, 2005). As this situation (all other factors occur at non-limiting levels) is unlikely to occur in the natural world, the meaningful determination of the limiting effect of environmental variables on species response requires the use of non-standard statistical methods. In quantile regression, any relative limit of the observed data distribution may be modelled (Cade and Noon, 2003; Yu et al., 2003; Koenker, 2005). Predictions from upper quantiles overestimate species abundance to illustrate the spatial distribution of the maximum abundance in ideal environmental conditions (Vaz et al., 2008). When HS models are developed through regression quantiles (Planque et al., 2008) or environmental envelopes (Guisan and Zimmermann, 2000), predicted maps tend to describe potential spatial patterns or the "potential habitat" of species, i.e. all possible areas with conditions suitable for the presence or high abundance of a species. For instance, Eastwood et al. (2001) applied 
regression quantiles to estimate variations in spawning HS for the common sole in the Eastern Channel and southern North Sea, using data on the distribution of sole eggs. Eastwood et al. (2003) used the same method to assess the limits of spatial extent and suitability of nursery grounds for the same species on the same area from coastal trawl survey data. Vaz et al. (2008) further developed the methodology and applied it to several species of the same marine region. In a worldwide approach, Cheung et al. (2009) used a bioclimate envelope model to represent distributional ranges of more than one thousand exploited marine fish and invertebrates.

HS maps showing potential habitats are less likely to underestimate species responses to the environment (Eastwood et al., 2001) and the related value of the habitat; and therefore, they have potential benefits for precautionary management of living resources. By using this technique, there is more chance of achieving a good level of protection than through realized HS models (Eastwood et al., 2003) in the case of population depletion. Indeed, when fish populations are depleted, it becomes difficult to analyse habitat suitability with regards to central tendency, as the distribution of the population may be reduced (Le Pape et al., 2007; Grüss et al., 2011a; Planque et al., 2011a). Applying regression quantiles to produce maps of the upper limits of suitability is important from a conservationist perspective, but would hardly be applied in a systematic way to ecosystems where impacts are diverse and the protection of the whole suitable area for any species is generally not possible (Vinagre et al., 2006). In the context of habitat conservation and sustainable fisheries management, an approach describing and comparing potential and realized HS maps can prove very useful in this respect.

\subsection{Analysing the impact of anthropogenic pressures}

HS maps have been used in different backward or forward predictive approaches to estimate quantitatively the past or future consequences of anthropogenic pressures on fish population renewal and related fisheries. Indeed, analysing the consequences of pressures at the level of HS maps appears to be appropriate (Courrat et al., 2009; de Jonge et al., 2012). For instance:

Rochette et al. (2010) developed quantitative maps of common sole nursery habitats in the Eastern Channel by using an HS model based on bathymetry and sediment structure. Next, they used historical maps of the highly degraded Seine estuary to build HS maps of this estuary from 1850. This backward predictive approach showed that habitat loss in the Seine estuary has led to a more than $40 \%$ decrease in its nursery capacity. The loss related to both land reclamation and degradation of residual habitat quality was assessed at the Eastern channel population scale and for the related fisheries, at nearly $17 \%(15-32 \%)$. On the basis of these estimates, Cordier et al. (2011) addressed the fishery-related macroeconomic impact of this loss and that of the possible restoration of these nursery areas.

From an HS model, Le Pape et al. (2004) emphasised the negative role of an invasive mollusc, the slipper limpet, on juvenile sole density in the Bay of Biscay. The density of juvenile sole was significantly lower where this invasive species was established. On these bases, Kostecki et al. (2011) interpolated maps of (i) slipper-limpet and (ii) flatfish spatial distributions over the past decades in a coastal Bay of the Western Coast of France, where slipper limpet invasion is particularly high. This proliferation has led to a decrease in available surface for four flatfish species, and this highlighted the negative influence of slipper-limpet extension on the nursery function of this bay.

HS delineates geographic areas within which ranges of environmental factors define the presence or high abundance of a particular species or species assemblage. In this context, climate scenarios are of great interest to report correlations between the past or current 
geographical distribution of a species, as are some climate variables to extrapolate a future distribution (Fig. 2). Such studies (e.g. Murrawski, 1993; Heikkinen et al., 2006; tTer Hofstede et al., 2010) generally assume that species distributions mirror climatic limitations; but alternatively, species may respond to shifting climate conditions by a shift in their realized niches. As a consequence, projections of future species distributions should be produced along with a quantification of the model"s uncertainty (Thuiller, 2004). Although modelling strategies for predicting the potential impact of the natural system present limitations, the bioclimate envelope approach can provide a useful first approximation of the impact of climate change on biodiversity. Cheung et al. (2009) projected the change in distributions of a large amount (> 1000) of marine fish and invertebrate species under climate change scenarios up to 2055 and showed that biodiversity in the high latitude regions is likely to be highly sensitive to climate change. On the basis of these estimates, Cheung et al. (2010) projected changes in fisheries catch potential and showed that climate change may lead to large-scale redistribution, with an increase in high-latitude regions and a decrease in the tropics.

Other types of scenarios may explore the effect of fisheries spatial management on species and community distribution (e.g. Mahevas and Pelletier, 2004) and in particular, the effect of MPAs and fishing closure areas (e.g. Stelzenmuller et al., 2011). However, the response to the reduction of fishing pressure could be complex, as population size may play an important role in the spatial extent of fish, leading to either extension or contraction of the population distribution through density-dependent processes or changes in the demographic structure of the population (Loots et al., 2010, Loots et al., 2011). The species distribution change resulting from diminishing disturbance and mortality may also be mediated though interspecific relationships at the community level (Colleter et al., 2012; Mesnildrey et al., 2013).

In their very useful contribution for a better use of scenarios, Börjeson et al (2005) described procedures and classified scenarios into three categories: predictive (for forecasts and whatif scenarios), explorative (to look at several different types of outcomes) and normative (to reach specific targets or visions). They stressed that too often, "a certain technique is chosen without much consideration, when instead, an initial discussion should concern the types of scenarios that are needed". In particular, one needs to be very much aware of the difference between interpolative scenarios (applied within the observed range of the explaining descriptors, i.e. the model calibration range) and extrapolative scenarios (where the model is applied outside its range of calibration and interaction), where situations may be influenced by processes that it does not account for.

\subsection{Using quantitative maps of essential fish habitats to design fisheries oriented MPA networks}

MPA networks have been recognized as an efficient spatial management tool for conserving marine biodiversity (Leathwick et al, 2008) but also for managing fishing resources and fisheries. Although there is a lack of scientific data on the species, the environment, and the existing pressures on the considered ecosystem, various ways to incorporate this information exist. HS maps are very powerful biological inputs in such processes (Elith and Leathwick, 2009; de Jonge et al., 2012). The initial approach, compiling HS maps for different species and life stages, was to combine layers into aggregated HS indices (Rubec et al., 1999). HS maps for all considered species and life stages may be stacked and a mean suitability index, possibly granting different weights to different species, may be computed for each cell of the map (Brown et al., 2000; Store and Jokimaki, 2003; Hattab et al., 2013). This initial approach was progressively discarded as conservation planning software became available. Henceforth, systematic conservation planning is extensively used worldwide. This target- 
driven approach helps to ensure that protected area networks achieve their goals of conservation and persistence of biodiversity (Margules and Pressey, 2000) and/or of sustainable spatial planning of fishing activities and other human activities with potential influence on fishing resources. Conservation softwares are suitable tools integrating ecological as well as socioeconomic aspects and enhance technical co-operation between the decision makers and the scientists (de Jonge et al., 2012). Systematic conservation planning based on HS maps (Delavenne et al., 2012; Fig. 3) involves (i) producing a list of HS maps from the aforementioned procedure (Fig. 1) on a spatial structure dividing the planning region into a series of planning units, (ii) assigning a cost value to each planning unit (e.g., fishing spatial access priority mapping; Yates and Schoeman, 2013), and (iii) using computer software to identify priority areas for conserving biodiversity and ecosystem services (including fisheries), reducing fragmentation levels and minimizing planning unit costs. Several types of design models, and related conservation-planning software packages, are currently used to develop MPA networks. Marxan (Fig. 3), especially, allows the identification of planning unit portfolios that achieve conservation targets at near-minimal cost (Possingham et al., 2000). In contrast, Zonation aims at maximizing the conservation benefits at a fixed cost (Moilanen et al., 2005, 2009). Other software also exists, such as Cplan or ConsNet sofware platforms. Such systematic planning, using algorithmic tools, can improve biodiversity, ecological function and ecosystem service (including fisheries) representation in MPAs, while reducing the costs involved in meeting conservation targets (Malcom et al. 2012). The use of HS maps as inputs in such MPA network design tools allows to produce various conservation scenarios, depending on the ecosystem and biodiversity descriptors used, but also on the cost value (which may include both surface and boundary length considerations or the economic (e,g., fishing activities, Yates and Schoeman, 2013) and patrimonial value of the use of any planning units). However, uncertainty, inherent in the use of HS modelled maps for that purpose, has to be considered, especially when HS maps are based on presence only data. Until recently, the previously cited prioritization software was not able to deal with such uncertainty information; but new advances are on their way to fill this gap (Carvalho et al 2011).

\section{Conclusion}

Fisheries and environmental managers are faced with the multiple, often conflicting, demands of resource users when considering strategies for spatial planning and resource management. In coastal and marine systems, it is, therefore, important to help decision making in spatially explicit management (e.g. the establishment of fisheries-oriented MPAs or habitat restoration), as costs and other factors limit the amount of area that can be protected (Dahlgren et al., 2006). Related issues appear to be especially important in the context of the growing establishment of MPAs (Mora et al., 2006) both for conserving biodiversity and maintaining fish stocks (Leathwick et al., 2008).

The representation of the range of ecological functions and ecosystem services within sanctuary zones is a key component of planning frameworks (Malcom et al., 2012). A better understanding of fish habitat distribution for species of main interest for fisheries, and also for keystone and ETP species, at different life stages should be especially useful. It will enable scientists to fill knowledge gaps, help stakeholders to target their conservation efforts better so as to protect marine diversity, and to allow better spatial regulatory decisions for the longterm management of fisheries and habitat conservation (Beck et al., 2001; de Jonge et al., 2012). Therefore, the growing availability of full coverage environmental data, i.e. continuous maps of environmental descriptors, has made HS mapping increasingly easy to implement and has supplied a valuable procedure for the delineation of essential and effective fish habitats. The use of HS maps enables the integration of environmental and biological data, so as to gain a more in-depth understanding of HS and related fish distribution (Galparaso et 
al., 2009). The identification from HS maps of both essential and effective fish habitats, contributing significantly to fish populations, is particularly important to focus marine resource management on areas that are most critical and that should be considered of high importance for supporting viable populations. Indeed, in fisheries where exploited populations are regulated by habitat sensitive processes, MPAs protecting essential and effective habitats may be much more efficient than regulating fishing efforts and landings to maintain fish stocks (van de Wolfshaar et al. 2011) and associated fisheries (Grüss et al., 2011ab).

\section{Acknowledgements}

We wish to acknowledge financial support from the INTERREG IV A France-England crossborder European cooperation programme, co-financed by the European Regional Development Fund as part of the $\mathrm{CHannel}$ integrated Approach for marine Resource Management (CHARM) Phase 3 project and the Protected Area Network Across the CHannel (PANACHE) project. Juliette Delavenne received additional funding through a PhD studentship granted by the Syndicat Mixte Côte d"Opale (SMCO). Many colleagues were involved in fruitful and helpful discussions that generated and organized our ideas and made this paper a reality. We would like to thank them all, and especially Christophe Loots (IFREMER, France) and Benjamin Planque (Institute of Marine Research, Norway) who were closely involved in our advances in this research topic. We are also grateful to Sophie Pasquier for compiling references. We would also like to thank the editor, Professor V.N. de Jonge, and the two anonymous reviewers for their helpful comments.

\section{References}

Aarts, G., Fieberg, J., Brasseur, S., Matthiopoulos, J. 2013. Quantifying the effect of habitat availability on species distributions. J Anim. Ecol. 82(6), 1135-1145.

Araujo, M.B., Guisan, A., 2006. Five (or so) challenges for species distribution modelling. J. Biogeogr. 33, 1677-1688.

Ashcroft, M., French, K., Chisholm, L., 2010. An evaluation of environmental factors affecting species distributions. Ecol. Model. 222(3), 524-531.

Ashcroft, M., French, K., Chisholm, L.A., 2012. A simple post-hoc method to add spatial context to predictive species distribution models. Ecol. Model. 228, 17-26.

Austin, M.P., 2007. Species distribution models and ecological theory: a critical assessment and some possible new approaches. Ecol. Model. 200, 1-19.

Barbier, E., Hacker, S., Kennedy, C., Koch, E., Stier, A., Silliman, B., 2011. The value of estuarine and coastal ecosystem services. Ecol. Monogr. 81(2), 169-193.

Barry, S.C., Welsh, A.H., 2002. Generalized additive modelling and zero inflated coundt data. Ecol. Model. 157, 179-188.

Beck, M.W., Heck, K.L., Able, K.W., Childers, D.L., Eggleston, D.B., Gillanders, B.M., Halpern, B., Hays, C.G., Hostino, K., Minello, T.J., Orth, R.J., Sheridan, P., Weinstein, M.P., 2001. The role of nearshore ecosystems as fish and shellfish nurseries. BioScience 51(8), 633-641. 
Blowes, S., Connolly, S., 2012. Risk spreading, connectivity, and optimal reserve spacing. Ecol. Appl. 22, 311-321.

Boisclair, D., 2001, Fish habitat modeling: from conceptual framework to functional tools. Can. J. Fish. Aquat. Sci. 58, 1-9.

Börjeson, L., Höjer, M., Dreborg, K.H., Ekvall, T., Finnveden, G. 2005. Towards a user's guide to scenarios - a report on scenario types and scenario techniques. Environmental

strategies research, fms- Department of Urban studies, Royal Institute of Technology, Stockholm, Sweeden, ISSN 1652-5442.

Brown, K., Buja, K., Jury, S., Monaco, M., Banner, A., 2000. Habitat suitability index models for eight fish and invertebrate species in Casco and sheepscot bays, Maine. N. Am. J. Fish. Manage. 20, 408-435.

Brownman, H., Stergiou, K., Cury, P., Hilborn, R., Jennings, S., Lotze, H., Mace, P., Murawski, S., Pauly, D., Sissenwine, M., Stergiou, K.I., Zeller, D., 2004. Perspectives on ecosystem based approaches to the management of marine resources. Mar. Ecol. Prog. Ser. 274, 269-303.

Cade, B.S., Terrell, J.W., Schroeder, R.L., 1999. Estimating effects of limiting factors with regression quantiles. Ecology 80, 311-323.

Cade, B.S., Noon, B.R., 2003, A gentle introduction to quantile regression for ecologists. Front. Ecol. Environ. 1, 412-420.

Calama, R., Mutke, S., Tomé, J., Gordo, J., Montero, G., Tomé M., 2011. Modelling spatial and temporal variability in a zero-inflated variable: The case of stone pine (Pinus pinea L.) cone production. Ecol. Model. 222, 606-618.

Carvalho, S.B., Brito, J., Crespo, E.G., Watts, M.E., Possingham, H.P., 2011. Conservation planning under climate change: Towards accounting for uncertainty in predicted species distributions to increase confidence in conservation investments in space and time. Biol. Conserv. 144, 2020-2030.

Chase, J.M., Leibold, M., 2003. Ecological Niches: Linking Classical and Contemporary Approaches. University of Chicago Press, Chicago and London.

Cheung, W., Lam, V., Sarmiento, J., Kearney, K., Watson, R., Pauly, D., 2009. Projecting global marine biodiversity impacts under climate change scenarios. Fish Fish. 10, 235-251.

Cheung, W.L., Lam, V.W.Y., Sarmiento, J.L., Kearney, K., Watson, R., Zeller, D., Pauly, D., 2010. Large-scale redistribution of maximum fisheries catch potential in the global ocean under climate change. Glob. Change Biol. 16, 24-35.

Claudet, J., Osenberg, C.W., Benedetti-Cecchi, L., Domenici, P., García-Charton, J.A., Pérez-Ruzafa, A., Badalamenti, F., Bayle-Sempere, J., Brito, A., Bulleri, F., Culioli, J.M., Dimech, M., Falcón, J.M., Guala, I., Milazzo, M., Sánchez-Meca, J., Somerfield, P.J., Stobart, B., Vandeperre, F., Valle, C., Planes, S., 2008. Marine reserves: size and age do matter. Ecol. Lett. 11, 481-489.

Cogan, C., Todd, B., Lawton, P., Noji, T., 2009. The role of marine habitat mapping in ecosystem based management. ICES J. Mar. Sci. 66, 2033-2042. 
Colleter, M., Gascuel, D., Ecoutin, J.M., Toto de Morais, L., 2012. Modelling trophic flows in ecosystems to assess the efficiency of marine protected area (MPA), a case study on the coast of Sénégal. Ecol. Model. 232, 1-13.

Cordier, M., Pérez Agúndez, J.A., O"Connor, M., Rochette, S., Hecq, W., 2011. Quantification of interdependencies between economic systems and ecosystem services: an input-output model applied to the Seine estuary. Ecol. Econ. 70(9), 1660-1671.

Courrat, A., Lepage, M., Girardin, M., Laffargue, P., Nicolas, D., Lobry, J., Le Pape, O., 2009. Anthropogenic disturbance on nursery function of estuarine areas for marine species. Est. Coast. Shelf Sci. 81(2), 179-190.

Dahlgren, C.P., Kellison, G.T., Adams, A.J., Gillanders, B.M., Kendall, M.S., Layman, C.A., Ley, J.A., Nagelkerken, I., Serafy, J.E., 2006. Marine nurseries and effective juvenile habitats: concepts and applications. Mar. Ecol. Prog. Ser. 312, 291-295.

De Jonge, V.N., Pinto, R., Turner, R.K., 2012. Integrating ecological, economic and social aspects to generate useful management information under the EU Directives" „ecosystem approach". Ocean Coast. Manage. 68, 169-188.

De Knegt, H.J., Van Langevelde, F., Coughenour, M.B., Skidmore, W.F., De Boer, W.F., Heitkonig, I.M.A., Knox, N.M., Slotow, R., Van der Waal, C., 2010. Spatial autocorrelation and the scaling of species-environment relationships. Ecology 91(8), 2455-2465.

Delavenne, J., Metcalfe, K., Smith, R.J., Vaz, S., Martin, C.S., Dupuis, L., Coppin, F., Carpentier, A., 2012. Systematic conservation planning in the eastern English Channel: comparing the Marxan and Zonation decision-support tools. ICES J. Mar. Sci. 69, 75-83.

Diaz, R.J., Cutter, G.R., Able, K.W., 2003. The importance of physical and biogenic structure to juvenile fishes on the shallow inner continental shelf. Estuaries 26(1), 12-20.

Eastwood, P.D., Meaden, G.J., Carpentier, A., Rogers, S.I., 2003. Estimating limits to the spatial extent and suitability of sole (Solea solea) nursery grounds in the Dover Strait. J. Sea Res. 50(2-3), 151-165.

Eastwood, P.D., Meaden, G.J., Grioche, A., 2001. Modelling spatial variations in spawning habitat suitability for the sole Solea solea using regression quantiles and GIS procedures. Mar. Ecol. Prog. Ser. 224, 251-266.

Edgar, G., Stuart-Smith, R., 2009. Ecological effects of marine protected areas on rocky reef communities: a continental-scale analysis. Mar. Ecol. Prog. Ser. 388, 51-62.

Elith, J., Graham, C.H., Anderson, R.P., Dudik, M., Ferrier, S., Guisan, A., Hijmans, R.J., Huettmann, F., Leathwick, J.R., Lehmann, A., Li, J., Lohmann, L.G., Loiselle, B.A., Manion G., Moritz, C., Nakamura, M., Nakazawa, Y., McC. M. Overton, J., Townsend Peterson, A., Phillips, S.J., Richardson, K., Scachetti-Pereira, R., Schapire, R.E., Soberón, J. Williams, S.,

Wisz, M.S., Zimmermann, N.E. 2006. Novel methods improve prediction of species" distributions from occurrence data. Ecography 29, 129-151.

Elith, J., Leathwick, J., 2009. The contribution of Species Distribution Modelling to Conservation Prioritization. In: Moilanen, A., Wilson, K.A., Possignham, H. (Eds), Quantitative methods and computational tools, Oxford, UK, University Press, pp 196-210.

Fletcher, D., 2008. Confidence intervals for the mean of the delta-lognormal distribution. Environ. Ecol. Stat. 15, 175-189. 
Fodrie, F.J., Mendoza, G., 2006. Availability, usage and expected contribution of potential nursery habitats for the California halibut. Est. Coast. Shelf Sci. 68, 149-164.

Francis, M.P., Morrison, M.A., Leathwick, J., Walsh, C., Middleton, C., 2005. Predictive models of small fish presence and abundance in northern New Zealand harbours. Est. Coast. Shelf Sci. 64, 419-435.

Froeschke, J.T., Froeschke, B.F., 2011. Spatio-temporal predictive model based on environmental factors for juvenile spotted seatrout in Texas estuaries using boosted regression trees. Fish. Res. 111(3), 131-138.

Galparsoro, I., Borja, Á., Bald, J., Liria, P., Chust, G., 2009. Predicting suitable habitat for the European lobster (Homarus gammarus), on the Basque continental shelf (Bay of Biscay), using Ecological-Niche Factor Analysis. Ecol. Model. 220(4), 556-567.

Gell, F.R., Roberts, C.M., 2003. Benefits beyond boundaries: the fishery effects of marine reserves. Trends Ecol. Evol. 18, 448-455.

Gottschalk, T., Aue, B., Hotes, S., Ekschmittt, K., 2011. Influence of grain size on specieshabitat models. Ecol. Model. 222(18), 3403-3412.

Graham, M., 2003. Confronting multicolinearity in ecological multiple regression. Ecology 84(11), 2809-2815.

Grüss, A., Kaplan, D., Guénette, S., Roberts, C.M., Botsford, L., 2011a. Consequences of adult and juvenile movement for marine protected areas. Biol. Conserv. 144, 692-702.

Grüss, A., Kaplan, D.M., Hart, D.R., 2011b. Relative impacts of adult movement, larval dispersal and harvester movement on the effectiveness of reserve networks. PLOS One 6(5), e19960.

Guisan, A., Zimmermann, N.E., 2000. Predictive habitat distribution models in ecology. Ecol. Model. 135, 147-186.

Guisan, A., Thuiller, W., 2005. Predicting species distribution: offering more than simple habitat models. Ecol. Lett. 8, 993-1009.

Guisan, A., Lehman, A., Ferrier, S., Austin, M., Overton, J., Aspinall, R., Hastie, T., 2006. Making better biogeographical predictions of species distribution. J. Appl. Ecol. 43, 386-392.

Hall, S.J., 1998. The effects of fishing on marine ecosystems and communities. Blackwell Science, Oxford.

Halpern, B.S., Warner, R.R., 2002. Marine reserves have rapid and lasting effects. Ecol. Lett. 5, 361-366.

Harden J., 1968. Fish Migration. Edward Arnold, London, UK.

Hattab, T., Ben Rais Lasram, F., Albouy, C., Sammari, C., Romdhane, M.S., Cury, P., Leprieur, F., Le Loc'h, F. 2013. The Use of a Predictive Habitat Model and a Fuzzy Logic Approach for Marine Management and Planning. PLoS ONE 8(10), e76430.

Hayes, D.B., Ferreri, C.P., Taylor, W.W., 1996. Linking fish habitat to their recruitment dynamics. Can. J. Fish. Aquat. Sci. 53(1), 383-390. 
Heikkinen, R.K., Luoto, M., Araujo, M.B., Virkkala, R., Thuiller, W., Sykes, M.T., 2006. Methods and uncertainties in bioclimatic envelope modelling under climate change. Prog. Phys. Geog. 30, 751-777.

Hiddink, J.G., 2005. Implications of Liebig"s law of the minimum for the use of ecological indicators based on abundance. Ecography 28, 264-271.

Hilborn, R., Walters, C. J., 1992. Quantitative fisheries stock assessment: choice, dynamics and uncertainty. Rev. Fish. Biol. Fish. 2, 177-178.

Hirzel, A.H., Helfer, V., Metral, H.F., 2001. Assessing habitat suitability models with a virtual species. Ecol. Model. 145, 111-121.

Hirzel, A.H., Le Lay, G., Helfer, V., Randin, C., Guisan, A., 2006. Evaluating the ability of habitat suitability models to predict species presences. Ecol. Model. 199, 142-152.

Houde, E., 2008. Emerging from Hjort"s shadow. J. Northw. Atl. Fish. Sci. 41, 53-70.

Iles, T.C., Beverton, R.J.H., 2000. The Concentration hypothesis : The statistical evidence. ICES J. Mar. Sci. 57(2), 216-227.

Johnson, A., Jenkins, S., Hiddink, J., Hinz, H. 2012. Linking temperate demersal fish species to habitat: scales, patterns and future directions. Fish Fish. 14(3), 256-80.

Juanes, F., 2007. The role of habitat in mediating mortality during the post-settlement transition phase of temperate marine fishes. J. Fish Biol. 70, 661-667.

Kaplan, D.M., 2009. Fish life histories and marine protected areas: an odd couple? Mar. Ecol. Prog. Ser. 377, 213-225.

Koenker, R., 2005. Quantile Regression. New York: Cambridge University Press.

Kostecki, C., Rochette, S., Girardin, R., Blanchard, M., Desroy, N., Le Pape, O., 2011, Reduction of flatfish habitat as a consequence of the proliferation of an invasive mollusc. Est. Coast. Shelf Sci. 92, 154-160.

Kupschus, S., 2003. Development and evaluation of statistical habitat suitability models: an example based on juvenile spotted seatrout Cynoscion nebulosus. Mar. Ecol. Prog. Ser. 265, 197-212.

Lauria, V., Vaz, S., Martin, C.S., Mackinson, S., Carpentier, A., 2011. What influences European plaice (Pleuronectes platessa) distribution in the eastern English Channel? Using habitat modelling and GIS to predict habitat utilization. ICES J. Mar. Sci. 68, 1500-1510.

Le Pape, O., Chauvet, F., Mahévas, S., Lazure, L., Guérault, G., Désaunay, Y., 2003. Quantitative description of habitat suitability for the juvenile common sole (Solea solea, L.) and contribution of different habitats to the adult population in the Bay of Biscay (France). J. Sea Res. 50(2-3), 139-149.

Le Pape, O., Desaunay, Y., Guerault, D., 2004. Influence of an exotic mollusc, the American slipper limpet (Crepidula fornicata, L.) on habitat suitability for the juvenile common sole (Solea solea, L.) in the Bay of Biscay (France). Mar. Ecol. Prog. Ser. 277, 107-115.

Le Pape, O., Baulier, L., Cloarec, A., Martin, J., Le Loch, F., Désaunay, Y., 2007. Habitat suitability for the juvenile common sole (Solea solea, L.) in the Bay of Biscay (France): a quantitative description using indicators based on benthic fauna. J. Sea Res. 57, 126-136. 
Le Pape, O., Bonhommeau, S. (in press) Density dependence and trophic limitation on coastal and estuarine nursery grounds for marine fishes. Fish Fish.

Leathwick, J., Moilanen, A., Francis, M., Elith, J., Taylor, P., Julian, K., Hastie, T., 2008. Novel methods for the design and evaluation of marine protected areas in offshore waters. Conserv. Lett. 1, 91-102.

Legendre, P., Galzin, R., Harmelin-Vivien, M., 1997. Relating behavior to habitat : solutions to the fourth-corner problem. Ecology 78(2), 547-562.

Lester, S.E., Halpern, B.S., Grorud-Colvert, K., Lubchenco, J., Ruttenberg, B.I., Gaines, S.D., Airamé, S., Warner, R.R., 2009. Biological effects within no-take marine reserves: a global synthesis. Mar. Ecol. Prog. Ser. 384, 33-46.

Lichstein, J.W., Simmons, T.R., Shriner, S.A., Franzreb, K.E., 2002. Spatial autocorrelation and autoregressive models in ecology. Ecol. Monogr. 72(3), 445-463.

Loots, C., Koubbi, P., Duhamel, G., 2007. Habitat modelling of Electrona Antarctica (Myctophidae, Pisces) in Kerguelen by generalized additive models and geographic information system. Polar Biol. 30, 951-959.

Loots, C., Vaz, S., Planque, B., Koubbi, P., 2010. What controls the spatial distribution of North Sea plaice spawning population? Confronting ecological hypotheses through a model selection framework. ICES J. Mar. Sci. 67, 244-257.

Loots, C., Vaz, S., Planque, B., Koubbi, P., 2011. Understanding what controls the spawning distribution of North Sea whiting (Merlangius merlangus) using a multi-model approach. Fish. Oceanogr. 20, 18-31.

MacNally, R., 2000. Regression and model-building in conservation biology, biogeography and ecology: the distinction between - and reconciliation of - "predictive" and "explanatory"

models. Biodiversity Conserv. 9, 655-671

Mahévas, S., Pelletier, D. 2004. ISIS-Fish, a generic and spatially explicit simulation tool for evaluating the impact of management measures on fisheries dynamics. Ecol. Model. 171, 65-84.

Maggini, R., Lehmann, A., Zimmermann, N.E., Guisan, A., 2006. Improving generalized regression analysis for the spatial prediction of forest communities. J. Biogeogr. 33, 17291749.

Malcom, H., Foulsham, E., Pressey, R., Davies, P., Ongleton, T., Johnstone, N., Hessey, S., Smith, S., 2012. Selecting zones in a marine park: early systematic planning improves costefficiency; combining habitat and biotic data improves effectiveness. Ocean Coast. Manage. $59,1-12$.

Maravelias, C.D., 2001. Habitat associations of Atlantic herring in the Shetland area: influence of spatial scale and geographic segmentation. Fish. Oceanogr. 10(3), 259-267.

Margules, C.R., Pressey, R.L., 2000. Systematic conservation planning. Nature 405, $243-$ 253.

Martin, C.S., Carpentier, A., Vaz, S., Coppin, F., Curet, L., Dauvin, J.C., Delavenne, J., Dewarumez, J.M., Dupuis, L., Engelhard, G., Ernande, B., Foveau, A., Garcia, C., Gardel, L., Harrop, S., Just, R., Koubbi, P., Lauria, V., Meaden, G.J., Morin, J., Ota, Y., Rostiaux, E., 
Smith, R., Spilmont, N., Vérin, Y., Villanueva, C., Warembourg, C., 2009. The Channel habitat atlas for marine resource management (CHARM): an aid for planning and decisionmaking in an area under strong anthropogenic pressure. Aquat. Living Resour. 22, 499-508.

Martin, C.S., Vaz, S., Ellis, J., Coppin, F., Lauria, V., Carpentier, A., 2012. Modelled distributions of ten demersal elasmobranchs of the eastern English Channel in relation to the environment. J. Exp. Mar. Biol. Ecol. 418-419, 91-103.

McDonald, L., Manly, B., Huettmann, F., Thogmartin, W., 2013. Location-only and useavailability data: analysis methods converge. J. Anim. Ecol. 82(6), 1120-1124.

Mello, L.G.S., Rose, G.A., 2005. Using geostatistics to quantify seasonal distribution and aggregation patterns of fishes: an example of Atlantic cod (Gadus morhua). Can. J. Fish. Aquat. Sci. 62, 659-670.

Meng, L., Cicchetti, G., Raciti, S., 2005. Relationships between juvenile winter flounder and multiple scale habitat variation in Narraganset Bay, Rhode Island. Trans. Am. Fish. 134, 1509-1519.

Merckx B., Steyaert, M., Vanreusel, A., Vincx, M., Vanaverbke, J., 2011. Null models reveal preferential sampling, spatial autocorrelatio and overfitting in habitta suitability modelling. Ecol. Model. 222(3), 588-597.

Merow, C., Smith, M.J., Silander Jr., J.A., 2013. A practical guide to maxEnt for modelling species" distributions: what it does, and why inputs and settigs matter. Ecography 36, 10581069.

Mesnildrey, L., Gascuel, D., Le Pape, O., 2013. Marine Protected Areas and fisheries management: some criteria for ecological efficiency. Aquat. Living Resour. 26, 159-170.

Mieszkowska, N., Milligan, G., Burrows, M.T., Freckleton, R., Spencer, M., 2013. Dynamic species distribution models from categorical survey data. J. Anim. Ecol. 82(6), 1215-1226.

Moffitt, E.A., Botsford, L.W., Kaplan, D.M., O'Farrell, M., 2009. Marine reserve networks for species that move within a home range. Ecol. Appl. 19, 1835-1847.

Moilanen, A., Franco, A.M., Early, R.I., Fox, R., Wintle, B., Thomas, C.D., 2005. Prioritizing multiple-use landscapes for conservation methods for large multi-species planning problems.

Proc. Royal Soc. London, Ser. B: Biol. Sci. 272, 1885-1891.

Moilanen, A., Kujala, H., Leathwick, J. R. 2009. The Zonation framework and software for conservation prioritization. In Spatial Conservation Prioritization: Quantitative Methods and Computational Tools. In Moilanen, A., Wilson, K.A., Possingham, H.P.(Eds.), Oxford University Press, Oxford, UK, pp. 196-210

Moisen, G.G., Edwards, J.T.C., Osborne, P.E., 2006. Further advances in predicting species distributions. Ecol. Model. 199, 129-131.

Mora, C., Andréfouët, S., Costello, M.J., Kranenburg, C., Rollo, A., Veron, J., Gaston, K.J., Myers, R.A., 2006. Coral reefs and the global network of marine protected areas. Science 312(5781), 1750-1751.

Murawski, S.A., 1993. Climate change and marine fish distributions: forecasting from analogy. Trans. Am. Fish. Soc. 122, 647-658. 
Norcross, B., Holladay, B., Muter, F.J., 1995. Nursery areas characteristics of pleuronectids in coastal alaska, USA. Neth. J. Sea Res. 34(1-3), 161-175.

Norcross, B.L., Blanchard, A., Holladay, B.A., 1999. Comparison of models for defining nearshore flatfish nursery areas in Alaskan waters. Fish. Oceanogr. 8(1), 50-67.

Norcross, B.L., Muter, F.J., Holladay, B., 1997. Habitat models for juvenile pleuronectids around Kodiak Island, Alaska. Fish. Bull. 95, 504-520.

Oksanen, J., Minchin, P.R., 2002. Continuum theory revisited: what shape are species responses along ecological gradients? Ecol. Model. 157, 119-129.

Olden, J., Jackson, D., Peres-Neto, P., 2002. Predictive models of fish species distributions: a note on proper validation and chance predictions. Trans. Am. Fish. Soc. 131, 329-336.

Pelletier, D., Magal, P., 1996. Dynamics of a migratory population under different fishing effort allocation schemes in time and space. Can. J. Fish. Aquat. Sci. 53(5), 1186-1199.

Peterson, M., 2003. A conceptual view of environment-habitat-production linkages in tidal river estuaries. Rev. Fish. Sci. 11, 291-313.

Pineiro, G., Perelman, S., Guerschman, J.P., Paruelo, J.M., 2008. How to evaluate models: observed vs. predicted or predicted vs. Observed? Ecol. Model. 216, 316-322.

Planque, B., Bellier, E., Lazure, P., 2007. Modelling potential spawning habitat of sardine and anchovy in the Bay of Biscay. Fish. Oceanogr. 16, 16-30.

Planque, B, Buffaz, L., 2008. Quantile regression models for fish recruitment-environment relationships: four case studies. Mar. Ecol. Prog. Ser. 357, 213-223.

Planque, B., Loots, C., Petitgas, P., Lindstrom, U., Vaz, S., 2011a. Understanding what controls the spatial distribution of fish populations using a multi-model approach. Fish. Oceanogr. 20 (1), 1-17.

Planque, B., Bellier, E., Loots, C., 2011b. Uncertaineties in projecting spatial distributions of marine populations. ICES J. Mar. Sci. 68(6), 1045-1050.

Possingham, H.P., Ball, I., Andelman, S., 2000. Mathematical methods for identifying representative networks. In Quantitative Methods in Conservation Biology. Ferson S., Burgman M.A. (Eds) Springer, New York, pp. 291-306.

Power, M., 1993. The predictive validation of ecological and environmental models. Ecol. Model. 68, 33-50.

Power, M., Attrill, M.J., Thomas, R.M., 2000. Environmental factors and interactions affecting the temporal abundance of juvenile flatfish in the Thames estuary. J. Sea Res. 43, 135-149.

Randin, C.F., Dirnbock, T., Dullinger, S., Zimmermann, N.E., Zappa, M., Guisan, A., 2006. Are niche-based species distribution models transferable in space? J. Biogeogr 33, 16891703.

Riou, P., Le Pape, O., Rogers, S., 2001. Relative contributions of different sole and plaice nurseries to the adult population in the Eastern Channel: application of a combined method using Generalized Linear Models and a Geographic Information System. Aquat. Living Resour. 14, 125-135. 
Rivot, E., Prevost, E., Parent, E., Bagliniere, J.L., 2004. A Bayesian state-space modelling framework for fitting a salmon stage-structured population dynamic model to multiple time series of field data. Ecol. Model. 179, 463-485.

Rochette, S., Rivot, E., Morin, J., Mackinson, S., Riou, P., Le Pape, O., 2010. Effect of nursery habitat destruction on flatfish population renewal. Application to common sole (Solea solea, L.) in the Eastern Channel (Western Europe). J. Sea Res. 64, 34-44.

Rogers, S.I., 1992. Environmental factors affecting the distribution of sole (Solea solea(L.)) within a nursery area. Neth. J. Sea Res. 29(1-3), 153-161.

Rotenberry, J.T., Preston, K.L., Knick, S.T., 2006. GIS-based niche modeling for mapping species habitat. Ecology 87(6), 1458-1464.

Rubec, P.J., Bexley, J.C.W., Norris, H., Coyne, M.S., Monaco, M.E., Smith, S.G., Ault, J.S., 1999. Suitability modeling to delineate habitat essential to sustainable fisheries. Am. Fish. Soc. Symp. 22, 108-133.

Rushton, S.P., Ormerod, S.J., Kerby, G., 2004. New paradigms for modelling species distributions? J. Appl. Ecol. 41, 193-200.

Sale, P.F., Cowen, R.K., Danilowicz, B.S., Jones, G.P., Kritzer, J.P., Lindeman, K.C., Planes,

S., Polunin, N.V., Russ, G.R., Sadovy, Y.J., 2005. Critical science gaps impede use of notake fishery reserves. Trends Ecol. Evol. 20, 74-80.

Segurado, P., Araujo, M.B., 2004. An evaluation of methods for modelling species distributions. J. Biogeogr. 31, 1555-1568.

Sillero, N., 2010. Modelling suitable areas for Hyla meridionalis under current and future expansion scenarios. Amphibia-Reptilia 31, 37-50.

Sillero, N., 2011. What does ecological modelling model? A proposed classification of ecological niche models based on their underlying methods. Ecol. Model. 222(8), 13431346.

Sluka, R.D., Chiappone, M., Sullivan, Sealey, K.M., 2001. Influence of habitat on grouper abundance in the Florida Keys, U.S.A. J. Fish Biol. 58(3), 682-700.

Smith, A., Brown, C., Bulman, C.M., Fulton, E.A., Johnson, P., Kaplan, I., Lozano-Montees H., Mackinson, S., Marzloff, M., Shannon, L.J., Shin, Y.J., Tam, J., 2011. Impacts of fishing low trophic level species on marine ecosystems. Science 333(6046), 1147-1150.

Stefansson, G., 1996. Analysis of groundfish survey abundance data: combining the GLM and delta approaches. ICES J. Mar. Sci. 53, 577-588.

Stelzenmuller, V., Schulze, T., Fock, H.O., Berkenhagen, J., 2011. Integrating modelling tools to support risk-based decision-making in marine spatial management. Mar. Ecol. Prog. Ser. 441, 197-212.

Stewart-Koster, B., Boone, E., Kennard, M., Sheldon, F., Bunn, S., Olden, J., 2013. Incorporating ecological principles into statistical models for the prediction of species' distribution and abundance. Ecography 36(3), 342-353.

Stoner, A., 2003. What constitutes essential nursery habitat for a marine specis ? A case study of habitat form and function for queeen conch. Mar. Ecol. Prog. Ser. 257, 275-289. 
Stoner, A.W., Manderson, J.P., Pessuti, J.P., 2001. Spatially explicit analysis of estuarine habitat for juvenile winter flounder: combining generalized additive models and geographic information systems. Mar. Ecol. Prog. Ser. 213, 253-271.

Store, R., Jokimäki, J., 2003. A Gis-based multi-scale approach to habitat suitability modeling. Ecol. Model. 169, 1-15.

Ter Hofstede, R., Hiddink, J.G., Rijnsdorp, A.D., 2010. Regional warming changes fish species richness in the eastern North Atlantic Ocean. Mar. Ecol. Prog. Ser. 414, 1-9.

Thuiller, W., 2004. Patterns and uncertainties of species' range shifts under climate change. Glob. Change Biol. 10, 2020-2027.

Townsend Peterson, A., Papes, M., Soberon, J., 2008. Rethinking receiver operating characteristic analysis applications in ecological niche modeling. Ecol. Model. 213, 63-72.

Trimoreau, E., Archambault, B., Brind"Amour, A., Guitton, J., Le Pape, O., 2013, in press. Quantitative estimate of the function of soft sheltered productive coastal areas as essential flatfish nursery habitat. Est. Coast. Shelf Sci.

Van de Wolfshaar, K., HilleRisLambers, R., Gardmark, A., 2011. Effect of habitat productivity and exploitation on populations with complex life cycles. Mar. Ecol. Prog. Ser. 438, 175-184.

Vandeperre, F., Higgins, R.M., Sánchez-Meca, J., Maynou, F., Goñi, R., Martín-Sosa, P., Pérez-Ruzafa, A., Afonso, P., Bertocci, I., Crec"hriou, R., D"Anna, G., Dimech, M., Dorta, C., Esparza, Ó., Falcón, J.M., Forcada, A., Guala, I., Le Diréach, L., Marcos, C., OjedaMartínez, C., Pipitone, C, Schembri, P.J., Stelzenmüller, V., Stobart, B, Serrão Santos, R., 2011. Effects of no-take area size and age of marine protected areas on fishery yields: a meta-analytical approach. Fish Fish. 12, 412-426.

VanderWal, J., Shoo, L., Graham, C., Williams, S.E., 2009. Selecting pseudo absence data for presence only distribution modelling: How far should you stray from what you know. Ecol. Model. 220(4), 589-594.

Vasconcelos, R., Reis-Santos, P., Maia, A., Fonseca, V., Franca, S., Wouters, N., Costa, M., Cabral, H., 2010. Nursery use patterns of commercially important marine fish species in estuarine systems along the portuguese coast. Est. Coast. Shelf Sci. 86, 613-624.

Vasconcelos, R.P., Le Pape, O., Costa, M.J., Cabral, H.N. 2013. Predicting estuarine use patterns of juvenile fish with Generalized Linear Models. Est. Coast. Shelf Sci. 120, 64-74

Vaughan, I.P., Ormerod, S.J., 2005. The continuing challenges of testing species distribution models. J. Appl. Ecol. 42, 720-730.

Vaz, S., Carpentier, A., Coppin, F., 2007. Eastern English Channel fish assemblages: measuring the structuring effects of habitats on distinct sub-communities. ICES J. Mar. Sci. 64, 271-287.

Vaz, S., Martin, C.S., Eastwood, P.D., Ernande, B., Carpentier, A., Meaden, G., Coppin, F., 2008. Modelling species distributions using regression quantiles. J. Appl. Ecol. 45, 204-217.

Vinagre, C., Fonseca, V., Cabral, H.N., Costa, M.J., 2006. Habitat suitability index models for juvenile soles, Solea solea \& S. senegalensis, in the Tagus estuary: defining variables for species management. Fish. Res. 82, 140-149. 
Whaley, S.D., Burd, J.J., Robertson, B.A., 2007. Using estuarine landscape structure to model distribution patterns in nekton communities and in juveniles of fishery species. Mar. Ecol. Prog. Ser. 330, 83-99.

Yates, K., Schoeman, D. 2013. Spatial access priority mapping (SAPM) with fishers: a quantitative GIS method for participatory planning. PLOS One, 8, e68424.

Ye, Y., Al-Hussaini, M., Al-Baz, A., 2001. Use of generalized linear models to analyze catch rates having zero values: the Kuwait driftnet fishery. Fish. Res. 53, 151-168.

Yu, K., Lu, Z., Stander, J., 2003. Quantile regression: applications and current research areas. J. R. Stat. Soc.: Series D (The Statistician) 52, 331-350.

\section{Figures captions}

Figure 1: General procedure for building fish habitat suitability maps.

Figure 2: Simulating the effect of climate and population size on species distribution: specieshabitat relationship is modelled and HS numerical models are used to simulate the studied population distribution, based on different maps of habitat descriptors, reflecting changing environmental and demographic situations. Here, the effect of climate change and population size (spawning stock biomass $=\mathrm{ssb}$ ) scenarios on plaice (Pleuronectes platessa) distribution in the eastern English Channel.

Figure 3: Procedure for implementing conservation scenarios using conservation planning decision-support tools. The outputs were produced using Marxan. 
1. Choose fish species (exploited, keystone, endangered) and / or life stages to map From criteria based on ecosystem services and conservation

Needed knowledge : potential environmental factors driving fish habitat suitability

Needed data : - fish survey data (presence or density by species and/or life stages)

- exhaustive spatio-temporal description of environmental factors (maps)

2. Develop an habitat suitability model (HS)

2.1. Merge fish data and environmental factors

$\mathrm{n} 1$ potential environmental descriptors

n2 survey data

Map of 1 environmental descriptor (static or temporal)

$+\longleftarrow 1$ survey data (position, date) 1 associated value for this descriptor

2.2. Choose, fit then evaluate and validate an HS

Presence/Density (species or life stage $)=f($ environmental factors $)$

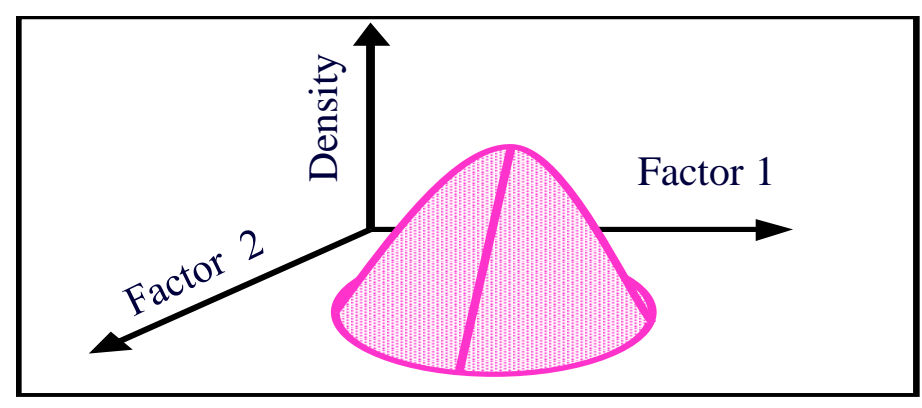

3. Create predicted maps

Maps of environmental descriptors
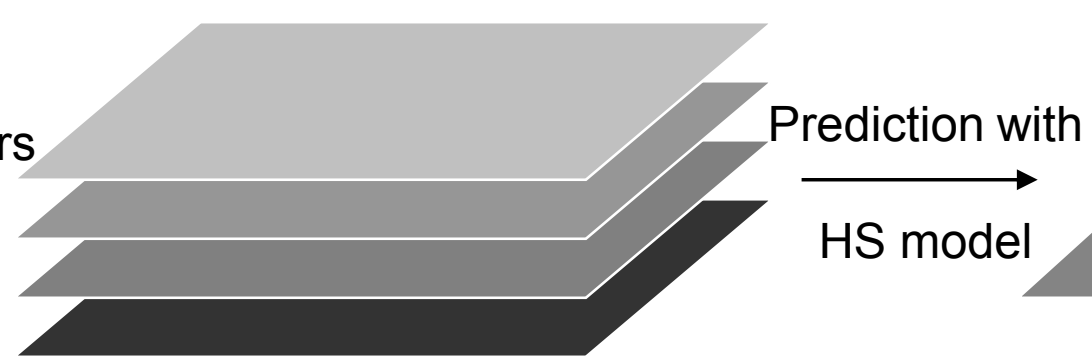

Habitat suitability map

4. Combine habitat suitability maps as layers in a GIS for management purpose 


\section{Habitat model $=$}

\section{Persistant predictors}
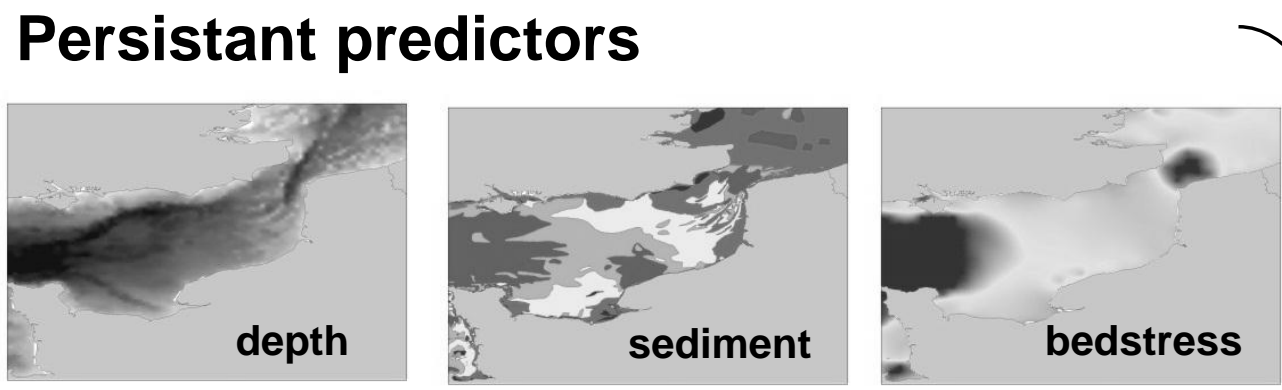

Changing predictors
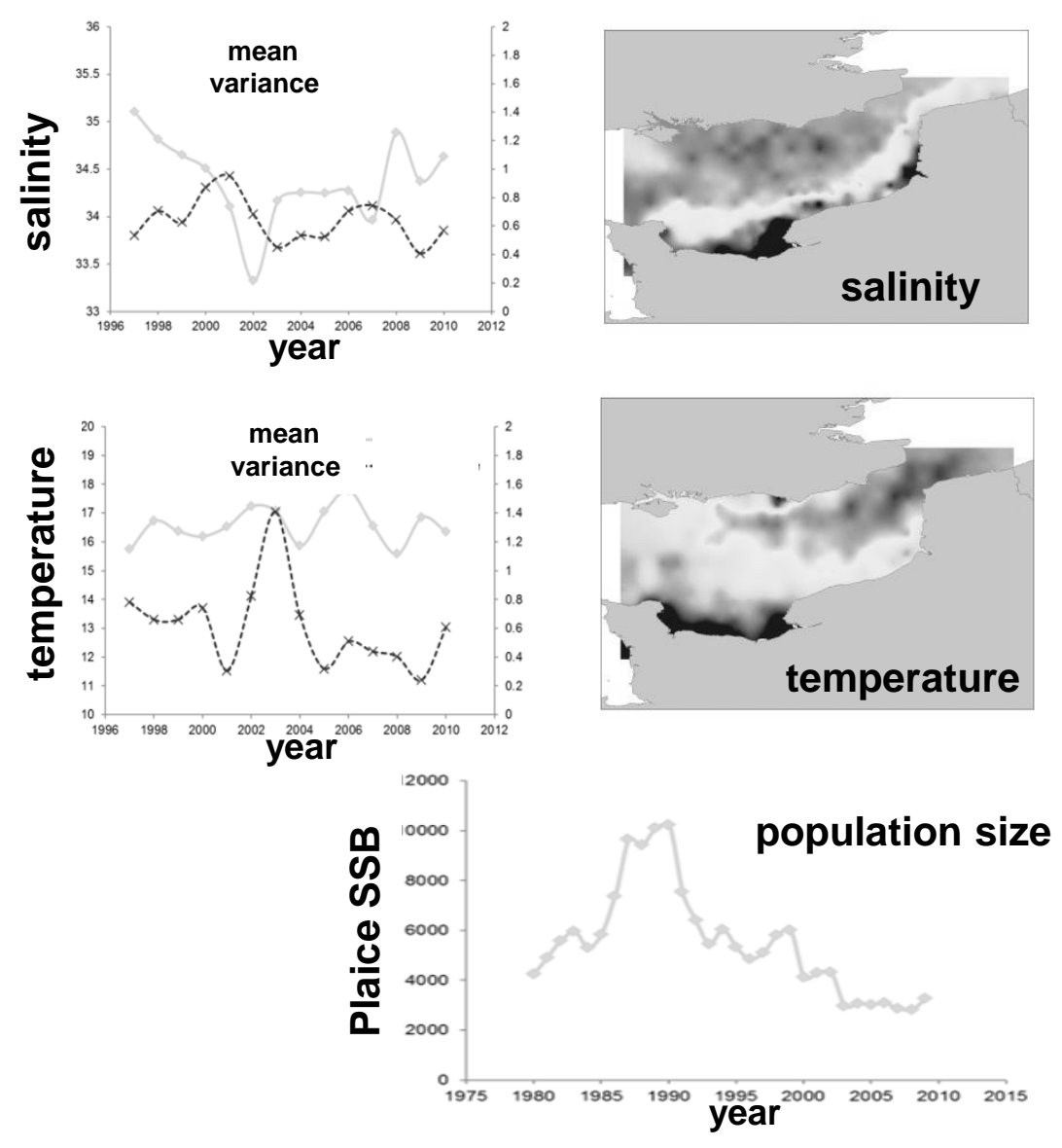

species response vs environment

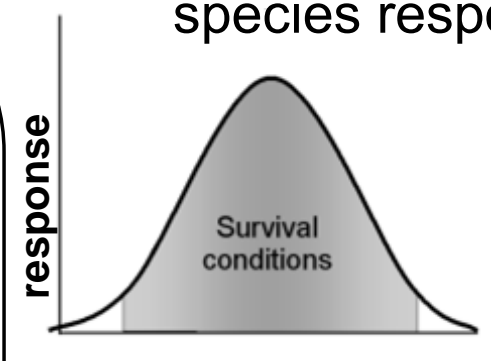

Env. factor Simulating effect of changes in:

- climate

- fishing mortality

- other habitat characteristics
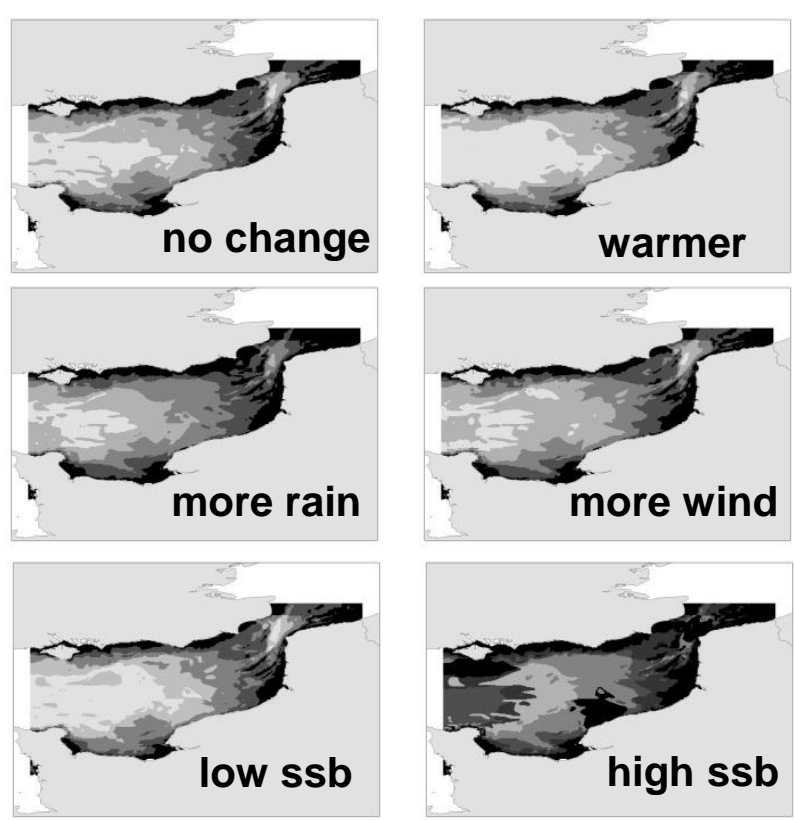

Predicted changes in species distribution under « what if» scenarios 


\section{Input maps}

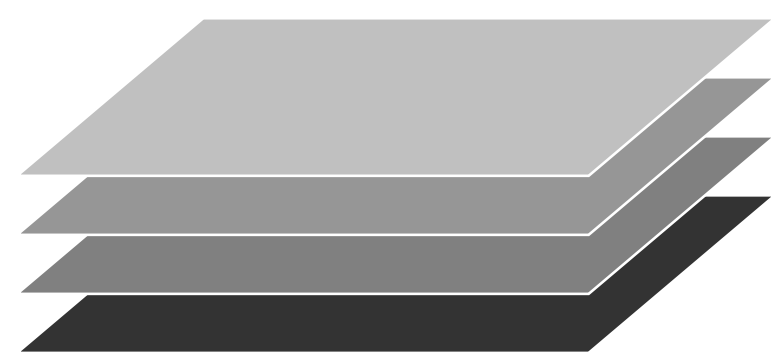

Species distribution maps

- Essential habitats (nurseries, spawning ground...)

- Economic datas (fisheries profitability...)

- Human uses (fisheries ground, Protected areas, windfarms..)

\section{Conservation planning software such as Marxan}

- Conservation targets

- Aggregation rate

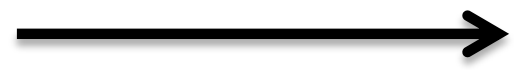

Aim: To propose a protected area network achieving conservation targets while minimizing the impact on the human uses.
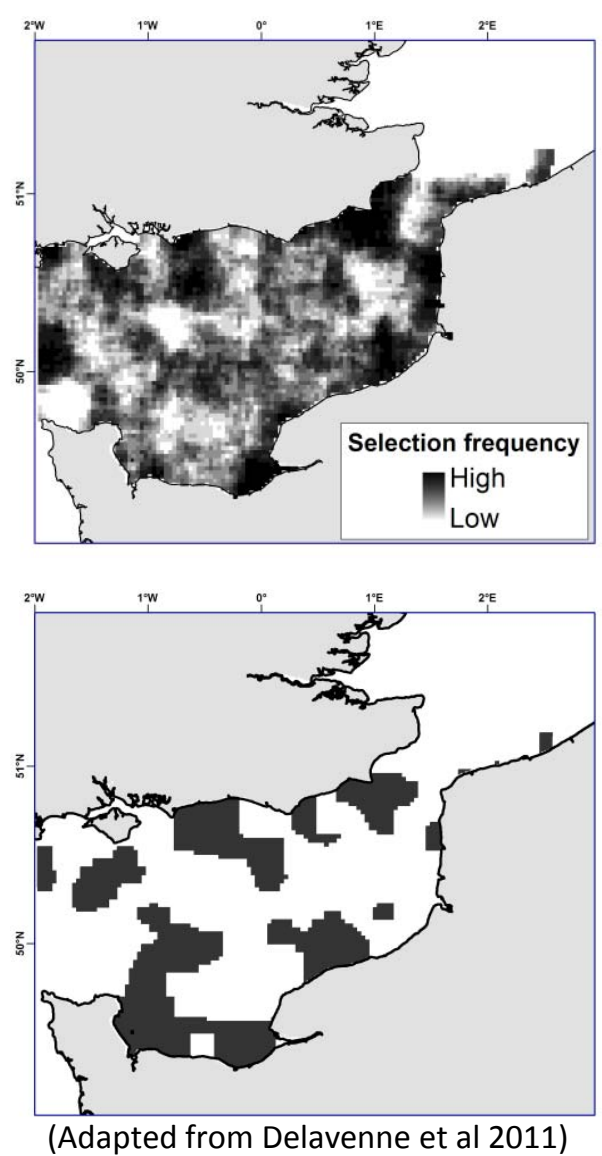

Conservation Value output

Priority-area output (proposed network) 